\title{
Using Means-End Chains for Analyzing Why Spectators Like Watching Sports Games via Online Live Streaming
}

\author{
Youhau Chen ${ }^{+}$and Kaili Wang \\ National Taiwan Sport University, Taoyuan City 33301, Taiwan
}

\begin{abstract}
Thanks to the advances in technology, more and more people are using online live streaming platform to watch sports games. By using a means-end chain (MEC) model and a laddering interview for data collection, this study attempts to explore why spectators watch sports games via online live streaming platform. Results show that the reasons lie in the easy access to information and the feeling of attending a game as provided by online live streaming platforms. Moreover, such platforms offer a variety of watching choices, which means freeing spectators from the limitations of local commercial broadcasting. These results indicate a future trend towards sports broadcasting online in order for spectators to watch games at lower costs in real time and to create a sense of participation, with rich broadcasting content provided.
\end{abstract}

Keywords: sport watching behaviours, online live streaming service, means-end chain, laddering interview, Taiwan.

\section{Introduction}

Thanks to the advance in technology, more and more people are using online live streaming platforms to watch sports games. In Taiwan, only a few commercial entities have the right to broadcast sports games. Commercial broadcasting is intended to attract audiences, but the content offered by sports television (TV) channel is quite limited, with baseball, basketball and tennis accounting for the majority of sports with live broadcasts.

In 2015, however, Lamigo, a team affiliated with the Chinese Professional Baseball League (CPBL), the top-tier baseball league in Taiwan, started using online live streaming to broadcast its games. The anchoring style is so interesting that the live streaming is like an entertainment show, engaging many fans into watching the channel. This has also successfully promoted Lamigo's brand image [1]. This successful experience has prompted other CPBL teams not only to apply Lamigo's live-streaming strategy, but also to sell their own broadcasting rights. This way, teams may have the power to decide the broadcast content, and find it easier to promote their images.

A company with a top-selling product must clearly understand what its customers really want. Therefore, this study attempts to explore what spectators want, who watch sports games via online live streaming, and what they would experience. Another goal is to enable sport teams to learn a new marketing strategy.

\section{Method}

\subsection{Means-end chain approach (MEC)}

In choosing an online live streaming platform over other channels, viewers must make a multitude of decisions. To explore this, marketing researchers must understand what factors would affect their decision, and what values they would like to acquire. The MEC approach helps answer these questions [2] (Olson \& Reynolds, 1983) as it can explain how consumers acquire some values by shopping. These values are linked

\footnotetext{
+ Corresponding author. Tel.: +886 988-312-885.
}

E-mail address:_good19930630@gmail.com. 
by means of their perception of the attributes of the product to be purchased and the consequences acquired after purchase. In short, the method clearly explains the links in the chain "attributes $\Rightarrow$ consequences $\Rightarrow$ values" that exists in consumer's decision-making process.

The MEC approach has three levels. Level 1 is the "attributes" of products/services that can be observed. Level 2 is the "consequences" about the consumer experience. Finally, Level 3 deals with the ultimate "values" that consumers pursue [2] (Olson \& Reynolds, 1983). The MEC is summarized as follows:

(1) Attributes

Attributes are the characteristics of the product/service perceived by the consumer [3] (Reynolds, Dethloff \& Westberg, 2001). They also mean the characteristics of the product/service that consumers can be aware of directly before purchase, such as appearance, look and brand.

(2) Consequences

Consequences are the effect on a consumer while the product/service is being purchased or used [4] (Gutman \& Michael, 1982) regarding the consequences of consumption as the physical or psychological effect resulting from the use of the product/service by the consumer, including fast services, low prices, and so on.

(3) Values

Values are what people want to get in their heart's desire ultimately, which plays an important role in their decision making [4] (Gutman \& Michael, 1982). For example, consumers believe some of the attributes can satisfy their demand and realize the values by generating benefits.

Figure 1 shows the structure of this study, where the MEC was a common tool to explore how the levels in the flow "Attributes $\Rightarrow$ Consequences $\Rightarrow$ Values" link with each other while consumers are watching sports games via online live streaming platforms.

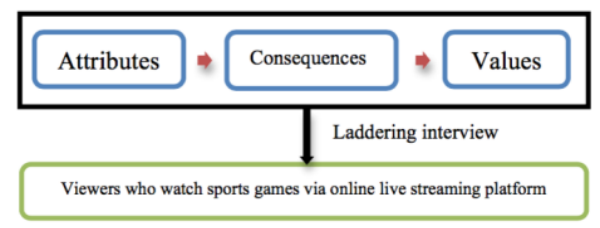

Fig. 1: Structure of methodology.

\subsection{Laddering interview}

Laddering interview, a method advanced by Reynolds and Gutman in 1988, was used to obtain the data for this study. It is mostly used to establish an MEC [5] (Reynolds \& Gutman, 1988) model. One-on-one interview is performed to understand how the consumer makes significant connections between the attributes of the product and himself/herself.

\subsection{Drawing a hierarchical value map (HVM)}

A good way to explain the links in an MEC is drawing a hierarchical value map, or HVM [4] (Gutman \& Michael, 1982) using data collected in a laddering interview [5] (Reynolds \& Gutman, 1988). Before drawing an HVM, it is required to prepare an implication matrix that presents the links between each level on a quantified basis. Drawings are based on the matrix.

(1) Implication matrix

An implication matrix uses rows and columns to present direct and indirect links between the levels (attributes, consequences and values). The greater the number inside the matrix is, the more closely the two levels are linked.

\section{(2) Drawing an HVM}

Inclusion of all links inside the implication matrix into an HVM will make the drawing so complicated that the truly important links would be ignored. So, it is advised to set a cut-off value, which can be used to determine how close the link should be in order to be included in the drawing. Currently there is no theoretical or statistical standard set for the cut-off value [6] (Grunert \& Grunert, 1995). 
In this study, the cut-off value is set to 4 , which means a direct link with the number being 3 or less will not be included.

\subsection{Subjects and sampling method}

As a pilot study, this study uses convenience sampling to find interviewees for the laddering interview. All interviewees have experience in watching sports games via an online live streaming platform. There are eight interviewees, aged 18-30, four male and the other four female.

\section{Result}

\subsection{Attributes}

Interviewees think that "Not broadcast live on TV," "Rich in content," "Convenience" and "Crazy about this game" are the most important attributes of using an online live streaming platform to watch sports games. Most interviewees indicate that in Taiwan, baseball, basketball and tennis take such a large proportion of game broadcasting on TV channels that fans of other sports (e.g. rugby) would need to watch games via an online live streaming platform. The convenience of such platforms is also important as viewers can watch games on the go using a smartphone.

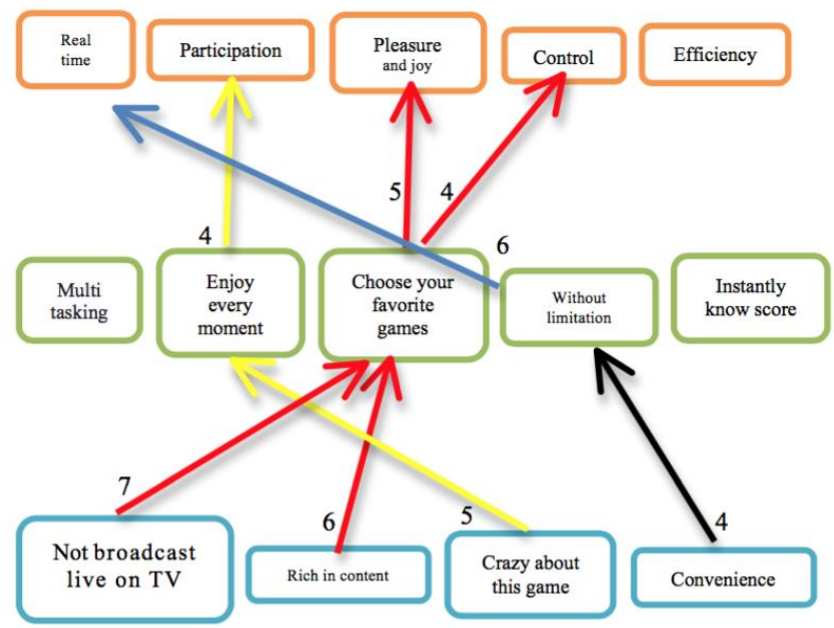

Fig. 2: Hierarchical value map.

\subsection{Consequences}

Interviewees think that "Enjoy every moment," "Choose your favorite games," "Multi-tasking" and "without limitation" are major consequences; Take Jeremy Lin for example. He is an American professional basketball player of Charlotte Hornets of the National Basketball Association and he is also the first American of Taiwanese descent to play in the league. In Taiwan, Lin fans can see almost each Hornets game. However, a San Antonio Spurs fan may need to watch Spurs games on an online live streaming platform. Last but not least, the consequence "multi-tasking" explains that some interviewees would like to watch games and do other things at the same time.

\subsection{Values}

Interviewees hold that "Real time," "Control," "Participation," "Efficiency "and "Pleasure and joy" are the most important values. For many, watching sports games is a common way to spend leisure time for pleasure and excitement. For spectators, real time is an extremely important value. They can keep up with all the twists and turns of a game, thereby gaining a sense of participation. Moreover, online live streaming allows viewers to choose the content that they really love rather than being limited by TV networks.

\subsection{Most important link chain}

This study derives three comparatively important link chains from Figure 2 based on the result of screening:

(1) "Convenience" $\rightarrow$ "Without limitation" $\rightarrow$ "Real time" 
Spectators watch sports games via online live streaming because of its convenience (without limitation). Finally, they can get information in real time.

(2) "Crazy about this game" $\rightarrow$ "Enjoy every moment" $\rightarrow$ "Participation"

The author of this study found that users of online live streaming are crazy about a sport less popular locally. This is why they would try a solution to watch live games of their interest. Live broadcasting would enable them to keep up with all the twists and turns of a game, just like they are watching games in the arena or stadium.

(3) "Not broadcast live on TV" or "Rich in content" $\rightarrow$ "Choose your favorite game" $\rightarrow$ "Pleasure and joy" and "Control"

Compared to the second link chain, viewers of this kind do not like watching sports games on TV, as their wanted games are not broadcast live on TV or they want to see more different types of sports. This is how they would feel satisfied. Interviewees also mention that they can choose the content they enjoy.

\section{Conclusion}

Compared to traditional live broadcasting on TV, online live broadcasting costs less and is more flexible. Online live streaming services can help develop product differentiation strategies, including anchoring style. This study concludes that the advantages of online live streaming are real time, rich in content, convenient, and a sense of participation.

On the other hand, in the laddering interview, few interviewees talk about its disadvantages, such as low resolution, difficulty in understanding the anchor's language, unsmooth video play and so on. Some interviewees, in particular, mentioned that they don't want to take part in discussion even if any chatroom functions can be enabled. This is because the language cannot be understood and the conversations simply make no sense. In this regard, one would say it is really a pity that the "sociability" feature does not work on online live streaming platforms. To solve this problem, platform administrators may have a moderator maintain the quality of conversation or invite celebrities or star athletes to take part in discussion. Furthermore, user experience can be upgraded by incorporating the concept of gamification into the platforms to engage more users.

In terms of commercial benefits, broadcasting rights may be infringed, thus influencing the operation of traditional TV sports networks. As for how to deal with this problem, they should consider more.

In short, online live streaming systems enable sports games to be broadcast more easily without replying much on professional broadcasters. This means a newly defined model of sports broadcasting.

\section{References}

[1] XIE, Dai-Ying (2016, March 21). Chinese Professional Baseball League 4 Teams all have their own online live broadcasting platforms. What About CPBL TV? Appledailynews. Retrieved from http://www.appledaily.com.tw/realtimenews/article/new/20160321/820965/

[2] Olson, J. C. \& Reynolds, T. J. (1983). Understanding consumers' cognitive structures: Implications for advertising strategy. In L. Percy \& A. Woodside (Eds.), Advertising and consumer psychology (pp.77-90). Lexington, MA: Lexington Books.

[3] Reynolds, T. J., Dethloff, C., \& Westberg, S. J.(2001). Advancements in Laddering. Understanding consumer Decision Making: The Means-End Approach to Marketing and Advertising Strategy. Lawrence Erlbaum Associates, publisher.

[4] Gutman, J., \& Michael K. M. (1982). Fashion life style, self-concept, shopping orientation, and store patronage: An integrative analysis. Journal of Retailing, 58(2), 64-86.

[5] Reynolds, T. J., \& Gutman, J. (1988). Laddering theory, method, analysis, and interpretation. Journal of Advertising Research, 28(1), 11-13.

[6] Grunert, K. G., \& Grunert, S. C. (1995). Measuring subjective meaning structures by the laddering method: Theoretical considerations and methodological problems. International journal of Research in Marketing, 12(3), 209-225. 